\title{
Correlations and Culture: A Study in Technique*
}

\author{
By Prof. Griffith Taylor
}

$G^{\mathrm{E}}$ EOGRAPHY links the four 'environmental sciences' of geology, physics, astronomy, botany, with the four 'human sciences' of history, anthropology, sociology and economics. There are vast uncharted areas on the borders of regional geography-the core of our discipline-which merge into the eight subjects specified. Among professional geographers, the great majority will always carry on the vital work in the central fields -but we may always hope for Raleighs, Drakes, Hawkins's, and Dampiers, who will explore far afield and extend our realms. They will perchance trespass on other empires; and doubtless some conservative historians and anthropologists will call them buccaneers or pirates. Dropping metaphor, I firmly believe that by applying techniques learnt in the realms of geography, biology and geologyand carried across to anthropology, history and sociologysuch pioneers will ultimately earn the respect of the leaders in the 'purer' social sciences. But I must caution any piratical young geographer who cruises in strange waters that his reward, if any, will probably be a posthumous one.

It was my use (on world maps) of the isopleth method in charting the criteria of race, in conjunction with the findings in W. D. Matthew's memoir "Climate and Evolution", which led me to publish the "Zones and Strata Classification of Races" in 1919. The general principles of this concept are illustrated in Fig. 1. Here three parallel cases of evolution are considered. All anthropologists will agree as to the explanation of the block diagram (Fig. $1 \mathrm{~A}$ ). Here we see zones of methods of transport (ox-team, horse-bus, motor-car and aeroplane) arranged round the city of Sydney-the only settlement of note for sixty

* From the presidential address to Section $\mathbf{E}$ (Geography) of the British Association, delivered in Cambridge on August 18. The following topics were discussed and illustrated: $(a)$ geography and the social sciences; $(b)$ geography and history; $(c)$ evolution of life and culture; $(d)$ relations of culture and race ; $(e)$ ecological approach to problems in culture; $(f)$ correlations in the distributions of languages ; $(g)$ ecological notes on the Aryan problem; $(h)$ the race of the Aryan-speakers; (i) graphs of culture-growth; (j) determinism versus possibilism, in Canada and Europe ; (k) culture in the twentieth century ; $(l)$ bibliography ; extracts from Sections $c, e, g$ and $j$ only have been selected. years in Australia. The 'strata' resulting from this evolution in Sydney and gradual migration to margin are indicated on the vertical edge of the block diagram. Clearly there is a common cradle-land, where commercial activity is greatest, in the centre of the zones-and the primitive types now occur precisely where they did not originate.

Turning to Fig. $1 B$, we find the same process illustrated in the evolution of the artiodactyls (or
BLOCK DIAGRAMS ILLUSTRATING THE 'ZONES AND STRATA' CONCEPT In each case the centre of evolution is in the centre of the zones, and the most primitive types have been thrust to the margins. The strata appear on the vertical edges (at right). All much generalized. even-toed mammals) based on data given by Matthew. The antelopes are earliest and are displaced farthest from the centre. The sheep are latest and still characterize the common cradleland. The fossil strata are in accord, using the palæontologist's 'law of superposition'. No biologist doubts that the zones and strata in the case of these mammals indicate the order of migration and of evolution for the artiodactyls.

I believe that primitive man was differentiated into the five major races long before the later races reached Western Europe. This evolution almost certainly took place in Asia and occurred before the last Ice Age. It certainly far antedated early Neolithic times. It is probable that the first Alpine peoples reached France (Solutré, etc.) in Aurignacian times; and Koeppen dates this as far back as 74,000 years ago. Neolithic times in France were only 8,000 years ago. Hence early 
man of such a primitive type can surely be considered as obeying the same laws of migration as the higher mammals. If now the pre-Columbian distribution of the major races (Negro, Mediterranean and Alpine) be plotted in a block diagram (Fig. $1 C$ ), we find a series of zones and strata closely resembling the two already charted. It is difficult to escape from the conclusion that the centre of Asia is the common cradleland where evolution progressed most actively in the case of primitive man-just as Matthew has shown it progressed most actively here to produce new types of the earlier mammals. Indeed, we can almost exactly parallel the spread of the rhinoceros from Asia with the spread of the negroes, while
Easter Island, yet I hope to demonstrate a culture sequence stretching across all this vast expanse.

Two remarkable features in Easter Island are the well-known stone statues and the undeciphered script incised on wooden tablets. There is no reasonable doubt (as the Routledges have shown) that the statues, with their bird-man decorations, are of the same culture-complex as is common in the Solomon Islands, some six thousand miles to the west (Fig. 2). Hevesy and Hunter are satisfied that the script, the only one used by Polynesians, is connected with the remarkable Mohenjo culture which flourished in the Indus region about 3000 B.c. It is true that objections have been raised by Métraux that the script was not understood by any living Polynesian, and that the tablets of mimosa wood, etc., are not likely to be many centuries old, some indeed being modern in origin. I think that these objections are not very relevant. Our own alphabet is said to originate from not very similar signs used by miners in Sinai, though all the links are not yet clear. The question surely is to determine the origins of the remarkable Easter script -and to my mind, the Mohenjo theory is plausible and indeed probable. Moreover, it offers a good illustration of clues which may be furnished by an ecological approach.

Let us consider some of the major culture changes in the Indus region. Gordon Childe has given data as to the races which

the spread of the Pleistocene Equidæ is the same as that of Alpine man.

The centre of stimulus in Fig. $1 A$ was the commercial progress in the city. In the case of the mammals and man it was the stimulating climate of south central Asia.

We may use as an illustration of the value of the 'zones and strata concept' that complex of races and cultures which characterizes the Indian and Pacific areas. I have had the advantage of travelling widely in Eastern Asia and in the Pacific, and this has focused my attention on the general principles underlying dispersion in this area. It is quite obvious that every widespread characteristic in Polynesia has migrated from west to east-and that any cultural contacts with America can be completely ignored in a general study. Let us examine the data in Easter Island-the farthest of these isolated groups from Asia (Fig. 2). It is almost 14,000 miles from the Caspian area to have been discovered at Mohenjo. Australoids, Mediterranean, Armenoids and Mongoloids were all present. There can be little doubt that the first settlers (before 3000 B.c.) were the aboriginal 'Australoids' who spoke a Munda language. Many members of this zone of peoples are now found 'pushed to the margin' in the East Indies and in Australia. It is represented by stratum 1 in Fig. 2. The general belief is that the Mohenjo culture was due to the later 'Mediterranean' races who spoke Dravidian languages This constitutes stratum 2, and in my opinion is to be linked with Dixon's 'Caspian race' in the Polynesian area.

We have little knowledge of the period 2500 B.c.1500 B.c. in India, when the great Aryan migrations overwhelmed North India. But it is significant that the earliest stone monuments in India, which are found at Rajagrha (Rajgir) near Patna, are of a cyclopean character quite unlike the work 
of the later Aryan builders, and rather resemble the mysterious early stone monuments of the Pacific. For example, the Jarasandha monument (of unknown date) is a square truncated pyramid $85 \mathrm{ft}$. wide and $28 \mathrm{ft}$. high. It is built of large uncemented blocks of stone 5 or $6 \mathrm{ft}$. across. It resembles the truncated pyramids and Maræ of Polynesia. I have suggested that this culturecomplex spread out as stratum 3. The AryanSanskrit complex (stratum 4) never reached Polynesia, but was carried to Java and dominated that region for several centuries after 200 B.c. In North India, Buddhism (stratum 5) flourished after 500 B.c. and was carried to Java about the eighth or ninth century of our era. It did not displace the older Hindu pantheism - but flourished alongside. Around A.D. 1400 the Moslems (stratum 6) conquered Java, and the Indian religions found a refuge in the island of Bali farther east, where they still flourish. It is not, of course, suggested that the Polynesians migrated from India, for they probably lived originally in south-east Asia. But their culture probably followed the same route as that used by the Buddhist and Moslem teachers in historic times.

We may dwell for a few minutes on the recent discoveries in the vicinity of Persia. In Mesopotamia, the earliest culture of Sumer is known as 'al Ubaid', and this contained copper tools and is younger than cultures from Susa and the adjacent Persian plateau.

To the north near Nineveh is the 'Tell Halaff' culture with wheeled vehicles, but with no metal. This is much older than anything discovered in Sumer near the Persian Gulf. Still older are the lowest cultures of Samarra in the same region, where they occur in debris seventy feet below a temple dated about 2450 B.c. Childe has corroborated my statement as to the cradleland of man, with his comment that the early cultures of China resemble those of Anau in Turkestan (Fig. 2). It is significant that Zoroaster, the first great religious teacher, lived in this same vital region. Thus we see that the centre of the zones of the races of man in Turkestan is also likely to be near the cradle of civilization.

We may use the stage-diagram to correlate our scanty knowledge as to the early wave-fronts of the Aryan languages. There are three fairly definite subdivisions of Aryan: (1) the early Kentum or ' $K$ ' speeches like Gaelic and Latin; (2) the Intermediate ' $P$ ' languages like Welsh (with which we may associate Teutonic and Greek for convenience); (3) the later Satem languages like Slav and Indian.

Turning to Fig. 3 some idea of our knowledge of the language distribution in Sumerian times is given in the lowest map of the series. At this time
Hamitic languages were used by the Pharaohs in Egypt, akin to those still spoken by the Berbers in the Atlas Mountains. Semitic languages characterized Arabia and Syria, as they still do. Sumerian

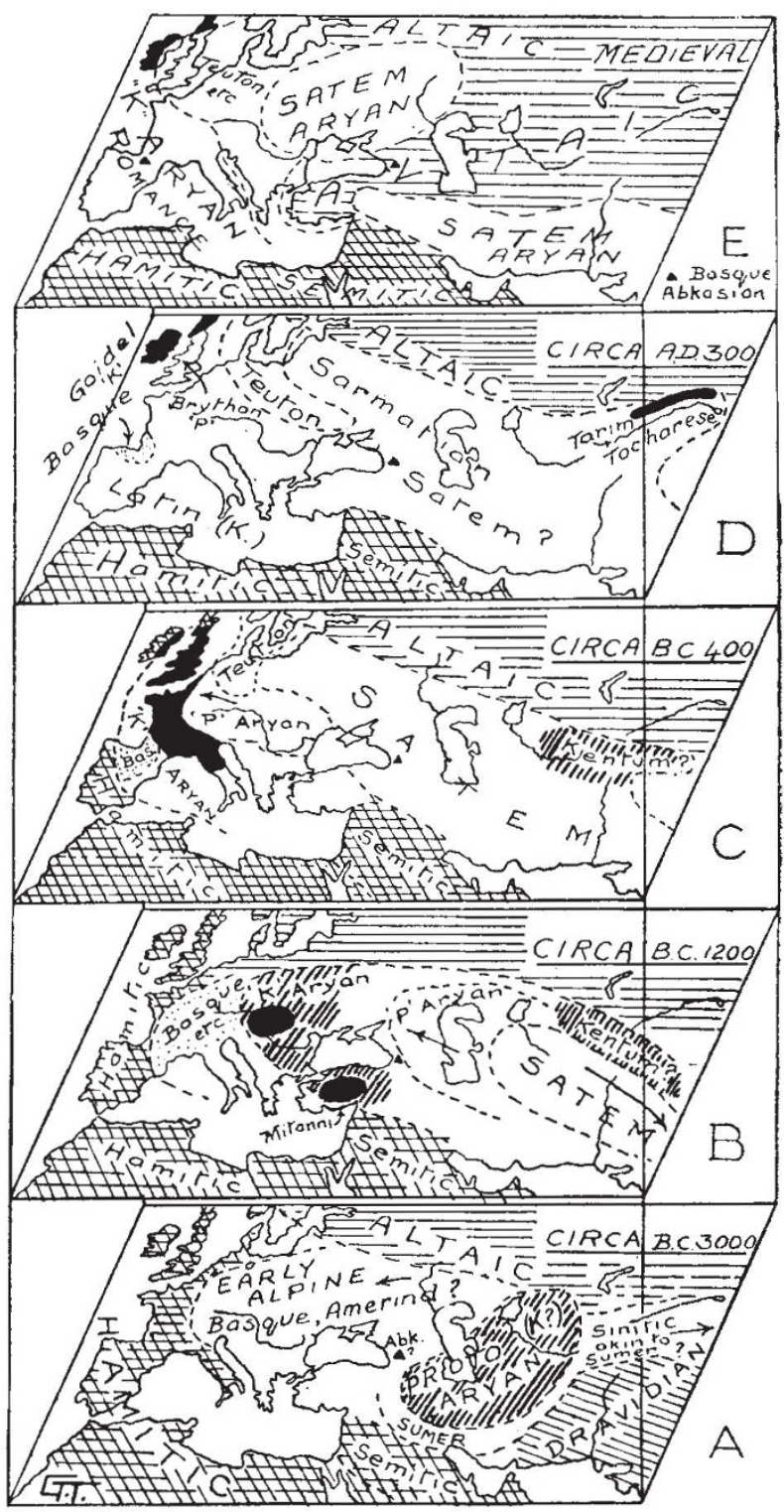

Fig. 3.

A stage-diagram giving a tentative reconstrucTION OF THE DISTRIBUTION OF EUROPEAN LANGUAGES AT VARIOUS EPOCHS.

Black areas are the Primitive (marginal) ' $K$ ' Aryan languages. It is suggested that the early Mediterranean race spoke Hamitic, and that the early Alpines spoke languages akin to Basque, Abkasian (and Amerind ?). Aryan developed near the Caspian Sea and spread out in waves. The outer 'ripple' $(K)$ was akin to Gaelic; the second $(P)$ akin to Welsh. The latest type was the Satem group.

itself has some resemblances to the Altaic, though its affinities are not yet clearly understood. In Europe at this early date there were racial allies 
of the present-day Hamitic-speakers-all of Mediterranean race-living in the western regions, who probably spoke Hamitic according to Rhys and Jones. Central Europe was occupied by early migration of Alpine 'Brakephs' (broadheads) of whose language we know nothing. It was almost certainly not Aryan, and something akin to 'Basque' seems most likely. In view of the important corridor linking Turkestan with China by way of the Tarim Basin, I have ventured to suggest that a linguistic kinship between early Chinese (Sinitic) and Sumerian or early Aryan is only to be expected.

In the second map (Fig. 3 at $B$ ), for the period around 1200 B.c., we are on surer ground. Vast migrations of 'Satem'-speakers had poured into India from Turkestan. The Hittites, who seem to have spoken an Aryan tongue somewhat akin to the Kentum Group, were in control of Anatolia. Semitic was now the chief language of Egypt and Mesopotamia.

In Central Europe (if we adopt the suggestions of Peake) Kentum languages were spoken in the regions east of the Alps, while Brythonic (one of the Intermediate ' $P$ ' type) was that used by the Cimmerians of the Ukraine and Caucasus areas. It seems logical to assume that many Satem-speakers still remained in Turkestan, and were perhaps allied to the Sarmatian tribes.

In the next map (for 400 B.c.) we see the first great Aryan conquest in the Near East, that of the Persians. They spoke a Satem language, and it is probable that their Sarmatian kin were occupying the European steppes about this time. The latter may have been the ancestors of the Slavs, who already seem to have settled in the Vistula Basin. Meanwhile the marginal $K$-speakers (Gaelic, etc.) had reached Britain and Ireland, and still occupied parts of France. The distribution of place-names in Central and Western Europe clearly shows the migration of waves of Gaelic and Welsh speakers across much of these areas.

The conditions some seven centuries later (A.D. 300) are shown in the next map, which deals with Europe during the zenith of the Roman Empire. The marginal primitive Aryan language Latin had been carried far and wide; so that it later gave rise to Italian, French and the other Romance tongues-which are clearly offshoots of the ' $K$ ' group of Aryan. Brythonic (Welsh) was spoken in England, South Scotland and Wales at this time, and probably in parts of the continent besides Brittany. Possibly some Hamitic dialects still persisted in the Scottish Highlands, as suggested by some of the Ogam inscriptions. Gaelic (a ' $K$ ' language) was spoken in Ireland and in most of Northern Scotland.

Of great interest is the discovery that a Kentum language, called Tocharese, was still in use north of the Tarim Basin in Central Asia about this time (Fig. 3 at $D$ ). Tocharese seems, however, to have some affinities with the Intermediate and Satem groups also. Hence it may well be fairly close to the generalized Aryan ancestor from which all three groups of Aryan have descended. It is suggested in the diagrams that this Kentum speech had been continuously used east of Turkestan since early Aryan times.

The medieval distribution of languages, and of the three subdivisions of Aryan, is shown in the top map. To-day Gaelic is almost the sole representative of a little altered primitive Aryan speech - though the much evolved derivatives of primitive Latin are still very important languages (Jespersen, 1894). Hamitic has died out in Europe. Altaic has encroached in Hungary and Finland, and displaced Hittite and Greek in Anatolia. Semitic has driven out Hamitic in much of North Africa. 'Satem' Aryan, in the form of Russian, is in turn displacing Altaic throughout much of the U.S.S.R.

The conclusion to be drawn from this tentative geographical approach to the Aryan problem is that the waves of language have spread from Turkestan towards India, Persia and Europe. There seems to be no support for the origin of Aryan in the German or Lithuanian regions, a theory which has been strongly upheld by a number of notable continental philologists.

During the twentieth century the trend of geography has been away from the belief of Ritter in 'providential' control, and from 'environmental' control as expounded by Ratzel, towards the 'possibilism' concept of Vidal de la Blache and his school. The latter geographers picture any particular region as offering almost innumerable possibilities of exploitation to man. Our material evolution, in their opinion, is essentially a matter of our own choice, depending on which of the possibilities we choose. I have come to a different conclusion, no doubt primarily owing to my experience in pioneer countries like Australia and Canada, where the possibilities offered by Nature to man are more meagre than in Great Britain or the United States. Indeed of these three schools, which we may label the theocratic, the geocratic and the 'we'-ocratic, I definitely belong to the second. However, I propose to illustrate by the correlative method first in a pioneer country like Canada, and secondly in the old-established culturecomplex of Europe, that man is not really a free agent-but definitely a product of his environment.

A generalized economic map about 1750 shows that fish, farms, and fur had expanded to Sas. katchewan. Some sixty years later, by 1810 , farming had spread approximately to Detroit; 
while Mackenzie was exploiting for furs the riverbasin named after him. By 1870 mining was becoming of some importance, and gold, silver and iron mines were being exploited both near the St. Lawrence and on the Fraser River. Still more important, Selkirk had, more than fifty years earlier, settled his isolated band of farmers on the silts of Lake Agassiz in the heart of the continent. About 1880 the modern migration to the wheatfields of the prairies began. In 1930 the whole north of the Dominion is being exploited not only for furs but also for metal mines; the latter in part by air-transport. Agriculture has covered most of the inland prairies, and will extend north (and into the clay belt). Manufactures have spread along the St. Lawrence from Montreal to Ottawa and Windsor, in large part owing to the bountiful water-power.

But while there have been these striking advances and changes in the type of industry, man has not really been a free agent. His advance from fur-hunting to wheat-growing is only possible where rain and sun and soil are satisfactory. All the fur country cannot be utilized for wheat, even if man so wishes. Using a foreign example, we shall never see hydro-electric power or coalfields leading to the development of factories in that half of the southern continent known as 'empty Australia', however much man may wish to replace the sparsest of pastoral occupation by betterpaying industries. On the other hand, it seems clear to me that in the future the immense coal resources of Alberta must inevitably be utilized, as the more accessible coalfields are used up elsewhere. Man may very probably some day 'choose' (as the 'possibilist' school would say) to give up ranching in the drier parts of Alberta, and turn to manufacturing based on the almost inexhaustible coal. But he is none the less controlled by his environment.

Exaggerating somewhat, I feel that man's part in the programme of a country's evolution is not unlike that of a traffic policeman. $\mathrm{He}$ can accelerate, slow or halt the traffic, but he does not alter its direction. This 'stop and go determinism' has no supporters among the historians, and not many even among geographers. But it expresses something of the conclusions that I have arrived at from my lengthy study of the difficult environments of Australia and Canada.

\section{Sense Perception and the Evolution of Colour and Pattern}

THE recent symposium* and discussion on "Sense Perception and the Evolution of Colour and Pattern" held under the auspices of Section D (Zoology) of the British Association at Cambridge directs attention to a field of inquiry where the artist, the naturalist, and the psychologist may meet.

In the interrelationships between animals of the same, or of different species-as between predator and prey, between rival males, or the opposite sexes, between parent and offspring, or between members of the group-characters which exert their influence from a distance, by sound, by sight, or scent, and the sensory equipment with which such stimuli are perceived, each play a vital part.

The study of such characters, to which Dr. J. S. Huxley has applied the term 'allæsthetic'1, involves various questions of wide interest. How far has the evolution of vision gone parallel with the development of characters serving as visual stimuli? What is the functional significance of the elaborately evolved stimulating equipment on one hand, and of the highly specialized sensory apparatus possessed for its appreciation by other animals?

* Speakers at the symposium were Dr. J. S. Huxley, Dr. H. B. Cott, Mr. D. Lack and Mr. I. H. Birkill.
The phenomena may be approached from various points of view: the nature of the allæsthetic characters themselves; the 'public' in relation to which they have evolved; the ecological significance of the relationship between the organisms concerned. Broadly speaking, the phenomena of adaptive coloration fall into three main classes, according to the visible results achieved-namely, concealment, advertisement, and disguise. The biological function of such elusive, attractive, or deceptive features varies widely according to circumstances. Through reduced visibility, they may facilitate the capture of food, or escape from the aggressor. Through increased conspicuousness, they may serve as a warning to enemies or a threat to rivals, as a courtship display, or a recognition mark. Through deceptive or mimetic effects, they may mislead the observer as to an animal's whereabouts, attitude, or identity.

Studies of adaptive coloration and visual perception have shown that there exists a close correlation between allæsthetic characters and the sensory equipment of the animals towards which they are directed and in relation to which they have evolved. Such characters therefore assume a new interest in the indirect light they throw upon questions of comparative psychology and sense perception. On these grounds it may be 